\title{
Article \\ Optimal Operation of Multiple Energy System Based on Multi-Objective Theory and Grey Theory
}

\author{
Bo $\mathrm{Hu}^{1,2}$, Nan Wang ${ }^{1,3, *(\mathbb{D}}$, Zaiming Yu ${ }^{1}$, Yunqing Cao ${ }^{4}{ }^{-0}$, Dongsheng Yang ${ }^{5}$ and Li Sun ${ }^{3}$ \\ 1 State Grid Liaoning Electric Power Co., Ltd., Shenyang 110006, China; dianlihubo@sina.com (B.H.); \\ yuzaiming007@163.com (Z.Y.) \\ 2 School of Electrical Engineering, Shenyang University of Technology, Shenyang 110870, China \\ 3 College of Electrical Engineering and Automation, Harbin Institute of Technology, Harbin 150006, China; \\ motor611@sina.com \\ 4 College of Physical Science and Technology, Yangzhou University, Yangzhou 225000, China; \\ yqcao@yzu.edu.cn \\ 5 College of Information Science and Engineering, Northeastern University, Shenyang 110057, China; \\ yangdongsheng@mail.neu.edu.cn \\ * Correspondence: dianwang_wangnan@163.com; Tel.: +86-138-4023-7992
}

Citation: Hu, B.; Wang, N.; Yu, Z.; Cao, Y.; Yang, D.; Sun, L. Optimal Operation of Multiple Energy System Based on Multi-Objective Theory and Grey Theory. Energies 2022, 15, 68. https://doi.org/10.3390/en15010068

Academic Editor: Ioana Pisica

Received: 12 November 2021

Accepted: 17 December 2021

Published: 22 December 2021

Publisher's Note: MDPI stays neutral with regard to jurisdictional claims in published maps and institutional affiliations.

Copyright: (c) 2021 by the authors. Licensee MDPI, Basel, Switzerland. This article is an open access article distributed under the terms and conditions of the Creative Commons Attribution (CC BY) license (https:// creativecommons.org/licenses/by/ $4.0 /)$.

\begin{abstract}
The manufacturing industry consumes electricity and natural gas to provide the power and heat required for manufacturing. Additionally, large amounts of electric energy and heat energy are used, and the electricity cost, amount of environmental pollution, and equipment maintenance cost are high. Thus, optimizing the management of equipment with new energy is important to satisfy the load demand from the system. This paper formulates the scheduling problem of these multiple energy systems as a multi-objective linear regression model (MLRM), and an energy management system is designed focusing on the economy and on greenhouse gas emissions. Furthermore, a variety of optimization objectives and constraints are proposed to make the energy management scheme more practical. Then, grey theory is combined with the common MLRM to accurately represent the uncertainty in the system and to make the model better reflect the actual situation. This paper takes load fluctuation, total grid operation cost, and environmental pollution value as reference standards to measure the effect of the gray optimization algorithm. Lastly, the model is applied to optimize the energy supply plan and its performance is demonstrated using numerical examples. The verification results meet the optimized operating conditions of the multi-energy microgrid system.
\end{abstract}

Keywords: multiple energy system; optimal operation; multi-objective linear regression model (MLRM); grey theory

\section{Introduction}

With the acceleration of industrialization and urbanization, the energy crisis, air pollution, and other problems have become increasingly serious [1]. In order to reduce environmental pollution and to improve power quality, the traditional power grid is gradually transforming into a smart grid [2]. A microgrid can be developed as an effective means for distributed power sources to connect to a smart grid [3]. A microgrid is composed of a distributed power supply, energy storage, and load and has unique advantages in improving the utilization rate of renewable energy. It can reduce the power interaction with a superior power grid, can alleviate the impact on a superior power grid [4], and plays an important role in lowering carbon emissions and in improving economic benefits.

At present, many scholars have conducted preliminary research on optimizing the operation of a microgrid. The authors of Reference [5] researched the optimization of operations of a microgrid based on the chaotic particle swarm optimization algorithm. The authors of Reference [6] combined the optimization of the operation of a microgrid with the game analysis method and proposed an optimal configuration model of an intermediate microgrid in the distribution network based on game theory. The authors of Reference [7] 
optimized the operation of a microgrid by modifying the hypermutation operator, which is the key mechanism of the CLONALG algorithm. Based on the non-dominated sorting genetic algorithm (NSGA-II), an optimal solution set under all objectives was found in [8] and used in the operation planning of a microgrid. However, the above multi-objective optimization method has weak dynamic response ability, and it is difficult to solve the microgrid optimization problem with real-time parameters in practical application. Although literature [9] adopts grey theory to optimize the model and improve the dynamic response speed, its optimization only targets economy and does not consider environmental problems such as exhaust emissions during micro-grid operation.

The grey multi-objective programming algorithm is a dynamic programming algorithm. The parameters in the model contain grey numbers to make up for the deficiency in general linear programming. It not only knows the optimal configuration under established conditions and dynamic conditions but also makes the model better reflect the objective reality [10]. Therefore, an intelligent operation control strategy of a multi-energy microgrid based on the grey multi-objective programming algorithm is proposed in this paper to effectively improve the economic costs and to reduce environmental pollution. First, mathematical models of the economic operation cost, exhaust emission, and equipment maintenance cost of a multi-energy microgrid are established. Second, a mathematical model of the power supply, heat supply, and cold supply balance is established. Then, a grey multi-objective linear programming solution model is established based on the mathematical model to economically and environmentally optimize the operation of a multi-energy microgrid. Finally, the effectiveness of the proposed strategy is verified using simulations.

The main contributions of this article are as follows:

(1) Combining wind power, photoelectric power, an energy storage system, and a gas system, the energy management system is designed with a focus on the economy and on greenhouse gas emissions.

(2) This paper proposes a grey multi-target linear planning algorithm and optimizes multitarget multi-energy management using the grey multi-target linear planning algorithm.

As Figure 1 shows, this article studies a multiple energy microgrid system model. This model was established according to the MES system architecture of an area in Liaoning Province. The solid line shows the flow of electricity, the two-way arrow shows the two-way flow of electricity, the dotted line shows the flow of heat energy, and the thin dotted line is the signal transmission line. As shown in Figure 1, the power generation information of all power generation equipment and the power consumption information of power consumption equipment, the heat provided by gas, electricity price, and fuel cost are transmitted to the SCADA control system. By using the control algorithm proposed in this paper, the control instructions of each unit are obtained and transmitted to the power generation and heating equipment. Figure 1 shows that, in addition to the power grid, photovoltaic cells, wind turbines, energy storage batteries, and the micro gas turbine can also supply electricity to the system. The heat is supplied by a gas turbine engine, an electric boiler, and thermal storage as the main sources. The cost of the system includes the electricity and gas costs. The equipment used to detect environmental pollution mainly considers the micro gas turbine and electric boiler system as well as the equivalent environmental pollution produced when generating power for the power grid. Additionally, all power generation and energy storage devices in the system need to be in the best state [11,12]. The following section discusses the objective function and the constraint conditions of a multiple energy microgrid system model for optimizing the operation of its equipment. 


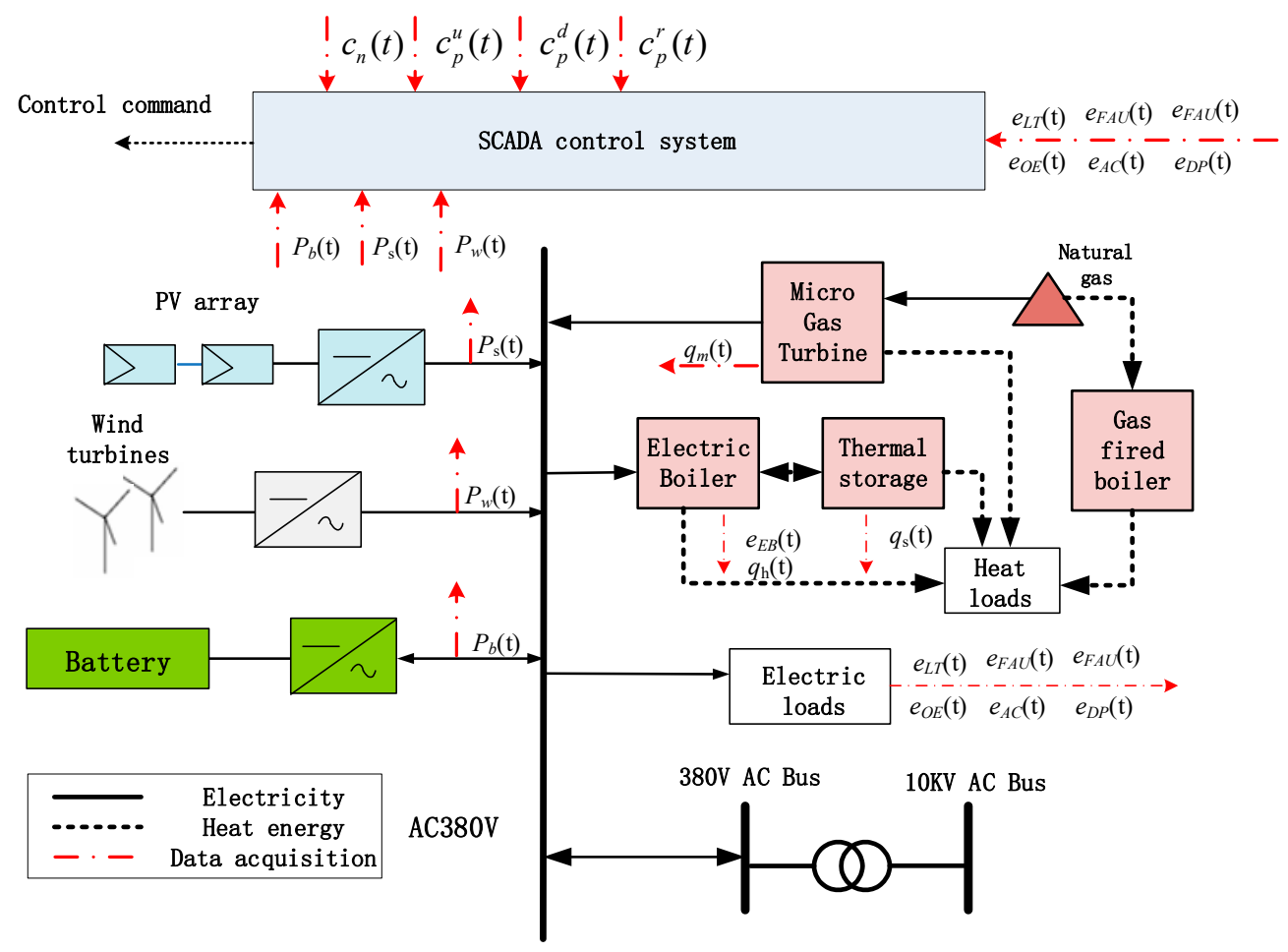

Figure 1. Multiple energy micro grid system model.

\section{Problem Formulations}

\subsection{Objective Function}

As shown in Figure 1, the micro grid system model includes minimizing the system economic operation cost, maintenance cost, and considering the environmental benefits, minimizing emissions of the system. Set the formulation as follows:

1. The energy consumption costs

$$
\min J_{c}=\sum_{t=1}^{T}\left[C_{t}^{p}\left(c_{p}^{d}(t), c_{p}^{u}(t), c_{p}^{r}(t), \tau\right)+C_{t}^{n}\left(c_{n}(t), v(t), \tau\right)\right]
$$

2. The waste gas emissions

$$
\begin{aligned}
\min J_{s}= & \sum_{t=1}^{T}\left[S_{t}^{p}\left(s_{s o}^{p}(t), s_{n o}^{p}(t), s_{c o}^{p}(t), p(t), \tau\right)+S_{t}^{n}\left(s_{s o}^{n}(t), s_{n o}^{n}(t), s_{c o}^{n}(t), v(t), \tau\right)\right. \\
& \left.+S_{t}^{m}\left(s_{s o}^{m}(t), s_{n o}^{m}(t), s_{c o}^{m}(t), v(t), \tau\right)\right]
\end{aligned}
$$

3. The components maintenance costs

The output of the wind turbines and photovoltaic cells is without artificial restrictions, so the major variable of the operation maintenance cost function are battery, electric boiler, gas turbine, and regenerator. The formulation is

$$
\begin{aligned}
\min J_{p} & =\sum_{t=1}^{T}\left[c_{b p}+c_{p v p}+c_{w p}+c_{E B P}+c_{m p}+c_{n p}+c_{s}\right] \\
& =\sum_{t=1}^{T}\left[c_{b p}+c_{E B P}+c_{m p}+c_{n p}+c_{s}\right]
\end{aligned}
$$

\subsection{Energy Balance Constraints}

1. The electricity supply and demand constraint

$$
\left[p(t)+p_{s}(t)+p_{w}(t)+p_{m}(t)+p_{b}(t)\right] \cdot \tau=e_{\text {load }}(t)
$$




$$
e_{\text {load }}(t)=e_{E B}(t)+e_{L T}(t)+e_{F A U}(t)+e_{O E}(t)+e_{A C}(t)+e_{D P}(t)
$$

2. Heating supply constraints

$$
q_{h}(t)=q_{E B}(t)+q_{E D}(t)+q_{s}(t) \cdot \operatorname{COPH}(t)+q_{m}(t) \cdot C O P M
$$

3. Cooling supply constraints

$$
q_{c}(t)=e_{A C}(t) \cdot \operatorname{COPA}(t)
$$

2.3. Cost of Electricity, Natural Gas and Equipment Maintenance

1. Cost of electricity

$$
C_{t}^{p}\left(c_{p}^{d}(t), c_{p}^{u}(t), p(t), \tau\right)= \begin{cases}c_{p}^{d}(t) \cdot p(t) \cdot \tau & \text { if } p(t) \geq 0 \\ c_{p}^{d}(t) \cdot p(t) \cdot \tau & \text { if } p(t) \leq 0\end{cases}
$$

$p(t) \leq 0$ is when the time is $t$ the upload electricity of system, $c_{p}^{r}(t) \cdot p(t)+c_{p}^{r}(t)$. $p_{\text {res }}(t)$ is the feed-in tariff of the clean energy.

2. Cost of natural gas

$$
C_{t}^{n}\left(c_{n}(t), v(t), \tau\right)=c_{n}(t) \cdot v(t) \cdot \tau
$$

3. Cost of equipment maintenance

The formula for calculating battery maintenance cost is:

$$
c_{b p}=a \sum_{t=1}^{T}\left[\left|z_{b}^{c}(t)-z_{b}^{c}(t-1)\right|+\left|z_{b}^{d}(t)-z_{b}^{d}(t-1)\right|\right]+b \sum_{t=1}^{T}\left[z_{b}^{c}(t)-z_{b}^{d}(t)\right]
$$

where $\sum_{t=1}^{T}\left[\left|z_{b}^{c}(t)-z_{b}^{c}(t-1)\right|+\left|z_{b}^{d}(t)-z_{b}^{d}(t-1)\right|\right]$ is the total number of cutting of the battery, $\sum_{t=1}^{T}\left[z_{b}^{c}(t)+z_{b}^{d}(t)\right]$ is the standby time of the battery, and $a, b$ denote the free parameters maintenance function.

4. Cost of electric boiler maintenance

$$
c_{B E P}=d \sum_{t=1}^{T}\left[\left|z_{B E}(t)-z_{B E}(t-1)\right|\right]+e \sum_{t=1}^{T} z_{B E}^{R}(t)
$$

where $\sum_{t=1}^{T}\left[\left|z_{B E}(t)-z_{B E}(t-1)\right|\right]$ is the number of electric heating boiler, $\sum_{t=1}^{T} z_{B E}^{R}(t)$ is load disturbance punishment function of the boiler system, and its computation formula is as follows:

$$
z_{B E}^{R}(t)= \begin{cases}1 & \text { if } p_{B E}(t) / p_{B E}(t-1) \geq 1.5 \quad \text { and } \quad p_{B E}(t-1) \neq 0 \\ 0 & \text { others }\end{cases}
$$

This equation sets out the harming system disturbance rate at $50 \%$ as benchmark, only counting the disturbance rates that are higher than the benchmark.

5. Cost of gas fired boiler maintenance

$$
c_{D E P}=d \sum_{t=1}^{T}\left[\left|z_{D E}(t)-z_{D E}(t-1)\right|\right]+e \sum_{t=1}^{T} z_{D E}^{R}(t)
$$

where $\sum_{t=1}^{T}\left[\left|z_{D E}(t)-z_{D E}(t-1)\right|\right]$ is the number of gas fired boiler, $\sum_{t=1}^{T} z_{D E}^{R}(t)$ is load disturbance punishment function of the boiler system, and its computation formula is as follows:

$$
z_{D E}^{R}(t)= \begin{cases}1 & \text { if } p_{D E}(t) / p_{D E}(t-1) \geq 1.5 \text { and } p_{D E}(t-1) \neq 0 \\ 0 & \text { others }\end{cases}
$$


This equation sets out the harming system disturbance rate at $50 \%$ as benchmark, only counting the disturbance rate that are higher than the benchmark.

6. Cost of micro gas turbine maintenance

$$
c_{m p}=f \sum_{t=1}^{T}\left|z_{m p}(t)-z_{m p}(t-1)\right|
$$

7. Cost of thermal storage maintenance

$$
c_{s}=g \sum_{t=1}^{T}\left[\left|z_{s}^{c}(t)-z_{s}^{c}(t-1)\right|+\left|z_{s}^{d}(t)-z_{s}^{d}(t-1)\right|\right]
$$

where $\sum_{t=1}^{T}\left[\left|z_{s}^{c}(t)-z_{s}^{c}(t-1)\right|+\left|z_{s}^{d}(t)-z_{s}^{d}(t-1)\right|\right]$ is the number of electric heating boiler.

\subsection{Constraints of Equipment Electricity and Heat Output}

1. Constraint of heat output of the electric boiler

$$
0 \leq e_{E B}(t) \cdot \operatorname{COP}(t)=q_{E B}(t) \leq z_{E B}(t) \cdot Q_{E B} \cdot \tau
$$

2. Constraint of heat output of the thermal storage

The heat capacity constraint equation of the thermal storage system is

$$
0 \leq q_{s r}(t)+q_{s} \leq Q_{s}
$$

Time continuous function of heat storage of the thermal storage system is

$$
q_{s r}(t+1)=\left[q_{s r}(t)+q_{s}\right] \mu_{h}
$$

where $\mu_{h}$ is the heat loss coefficient of the thermal storage.

Set the initial state equation for the thermal storage system as follow:

$$
q_{s r}\left(t_{0}\right)=Q_{s 0}
$$

Heat supply constraint equation of the thermal storage system is

$$
z_{s}^{c}(t) \underline{q}_{s i}-z_{s}^{d}(t) \bar{q}_{s o} \leq q_{s}(t) \leq z_{s}^{c}(t) \underline{q}_{s i}-z_{s}^{d}(t) \bar{q}_{s o}
$$

3. Constraint of heat output of the gas fired boiler

$$
0 \leq g_{E D}(t) \cdot \operatorname{COD}(t)=q_{E D}(t) \leq z_{D E}(t) \cdot Q_{E D} \cdot \tau
$$

4. Constraint of electricity output of the battery

SOC state constraint equation of the battery system is

$$
\frac{e_{i m p}}{\overline{e_{b}}}=\underline{S} \leq S O C(t) \leq 1
$$

where $\underline{S}$ is the battery SOC lower limit index. Setting its calculating formula as the ratio of the micro grid system's important load and the battery rated capacity, in order to ensure that even if the power grid failed suddenly, the important load would not suffer the impact.

Time continuous function of SOC state of the battery system is

$$
\operatorname{SOC}(t+1)=\operatorname{SOC}(t)(1-\sigma(t))+\frac{\eta_{b}(t)}{\overline{e_{b}}} I_{b}(t) \cdot \tau
$$

Set the initial state equation for the battery system as follows:

$$
\operatorname{SOC}\left(t_{0}\right)=K_{0}
$$


Electricity supply constraint equation of the battery system is

$$
z_{b}^{c}(t) \underline{p}_{b i}-z_{b}^{d}(t) \bar{p}_{b o} \leq p_{b}(t) \leq z_{b}^{c}(t) \bar{p}_{b i}-z_{b}^{d}(t) \underline{p}_{b o}
$$

5. Constraint of output of the micro gas turbine

The electricity output equation of the gas turbine system is

$$
p_{m}(t)=p_{m}^{R} \cdot x_{m}
$$

Constraint of electricity output of the gas turbine system is

$$
z_{m}(t) \cdot \underline{p}_{m} \leq p_{m}(t) \leq z_{m}(t) \cdot P_{m}^{R}
$$

The heat output equation of the gas turbine system is

$$
q_{m}(t)=\eta_{m} \cdot \operatorname{COP}_{m} \cdot p_{m}(t) \quad \eta_{m}=\left(1-\eta_{e}-\eta_{h}\right) / \eta_{e}
$$

Simplified, considering the gas turbine used for heat and electricity production as a basic proportional relation, the ratio is a coefficient of thermal efficiency.

The fuel consumption equation of the gas turbine system is

$$
v(t)=\alpha_{1} P_{m}^{R}+\alpha_{2} p_{m}(t)
$$

\section{Solution Methodology}

\subsection{Grey Multi-Objective Linear Programming Algorithm}

In grey multi-objective linear programming algorithm, whiting the grey number first is often necessary to solve the equation $[13,14]$. Note grey number $\widetilde{a}(\otimes)=[\underline{a}, \bar{a}]$, then the whitened value of $\widetilde{a}(\otimes)$ is $a(\otimes)$. Note that grey information of $\widetilde{a}(\otimes)$ is $\widetilde{a}(\otimes)=[\underline{a}, \bar{a}]$, and the whitened value $a(\otimes)$ can set as $a(\otimes) \in[\underline{a}, \bar{a}][15]$.

The grey multi-objective linear programming mathematics model of system is

$$
\begin{array}{r}
\max S=\widetilde{C}(\otimes) \cdot X \\
\text { st }\left\{\begin{array}{c}
\widetilde{A}(\otimes) \cdot X \leq \widetilde{B}(\otimes) \\
\widetilde{A} e q(\otimes) \cdot X=\widetilde{B} e q(\otimes) \\
X_{\min } \leq X \leq X_{\max }
\end{array}\right.
\end{array}
$$

where $C(\otimes)$ is grey target matrix, $A(\otimes)$ and $A e q(\otimes)$ are grey distribution matrix, while $B(\otimes)$ and $B e q(\otimes)$ are grey constraint matrix.

$$
\begin{gathered}
S=\left[S_{1}, S_{2}, \ldots, S_{k}\right]^{T} \\
X=\left[x_{1}, x_{2}, \ldots, x_{k}\right]^{T} \\
\widetilde{C}(\otimes)=\left[\begin{array}{cccc}
\widetilde{c}_{11}(\otimes) & \widetilde{c}_{12}(\otimes) & \ldots & \widetilde{c}_{1 n}(\otimes) \\
\widetilde{c}_{21}(\otimes) & \widetilde{c}_{22}(\otimes) & \ldots & \widetilde{c}_{2 n}(\otimes) \\
\ldots & \ldots & \ldots & \ldots \\
\widetilde{c}_{k 1}(\otimes) & \widetilde{c}_{k 2}(\otimes) & \ldots & \widetilde{c}_{k n}(\otimes)
\end{array}\right] \\
\widetilde{A}(\otimes)=\left[\begin{array}{cccc}
\widetilde{a}_{11}(\otimes) & \widetilde{a}_{12}(\otimes) & \ldots & \widetilde{a}_{1 n}(\otimes) \\
\widetilde{a}_{21}(\otimes) & \widetilde{a}_{22}(\otimes) & \ldots & \widetilde{a}_{2 n}(\otimes) \\
\ldots & \ldots & \ldots & \ldots \\
\widetilde{a}_{m 1}(\otimes) & \widetilde{a}_{m 2}(\otimes) & \ldots & \widetilde{a}_{m n}(\otimes)
\end{array}\right] \\
\widetilde{A} e q(\otimes)=\left[\begin{array}{cccc}
\tilde{a} e q_{11}(\otimes) & \widetilde{a} e q_{12}(\otimes) & \ldots & \tilde{a} e q_{1 n}(\otimes) \\
\widetilde{a} e q_{21}(\otimes) & \widetilde{a} e q_{22}(\otimes) & \ldots & \widetilde{a} e q_{2 n}(\otimes) \\
\ldots & \ldots & \ldots & \ldots \\
\widetilde{a} e q_{m 1}(\otimes) & \widetilde{a} e q_{m 2}(\otimes) & \ldots & \widetilde{a} e q_{m n}(\otimes)
\end{array}\right]
\end{gathered}
$$




$$
\begin{gathered}
\widetilde{B}(\otimes)=\left[\widetilde{b}_{1}(\otimes), \widetilde{b}_{2}(\otimes), \ldots, \widetilde{b}_{m}(\otimes)\right] \\
\widetilde{B} e q(\otimes)=\left[\widetilde{b} e q_{1}(\otimes), \widetilde{b} e q_{2}(\otimes), \ldots, \widetilde{b} e q_{m}(\otimes)\right]
\end{gathered}
$$

where $\widetilde{C}_{i j}(\otimes)=\left[\underline{c}_{i j}, \bar{c}_{i j}\right], i=1,2, \ldots, k, j=1,2, \ldots, n, \widetilde{a}_{i j}(\otimes)=\left[\underline{a}_{i j}, \bar{a}_{i j}\right], i=1,2, \ldots, m$, $j=1,2, \ldots, n, \widetilde{b}_{j}(\otimes)=\left[\underline{b}_{i}, \bar{b}_{i}\right], i=1,2, \ldots, m$.

By consuming coefficient of the grey value to whiten, the expression is

$$
\begin{gathered}
c_{i j}(\otimes)=\left(1-\theta_{c}\right) \bar{c}_{i j}+\theta_{c} \underline{\underline{c}} i j \quad i=1,2, \ldots, k, j=1,2, \ldots, n \\
a_{i j}(\otimes)=\left(1-\theta_{a}\right) \bar{a}_{i j}+\theta_{a} \underline{a}_{i j} \quad i=1,2, \ldots, m, j=1,2, \ldots, n \\
b_{j}(\otimes)=\left(1-\theta_{b}\right) \bar{b}_{i j}+\theta_{b} \underline{b}_{i j} \quad i=1,2, \ldots, m
\end{gathered}
$$

where $\theta_{c} \in[0,1], \theta_{a} \in[0,1], \theta_{b} \in[0,1]$, they respectively are the coefficients of $c_{i j}(\otimes), a_{i j}(\otimes)$, $b_{j}(\otimes)$, the corresponding grey multi-objective linear programming solution is $S\left(\theta_{\mathcal{c}}, \theta_{b}, \theta_{a}\right)$, and the feasible solution domain is $R\left(\theta_{b}, \theta_{a}\right)$.

\subsection{Model Solving Method}

The whitened optimal solution matrix is an n-order zero matrix, and the whitened probability integral matrix is an m-order zero matrix. Then, the technical parameters of the power generation and energy storage modules are denoted $A$ and Aeq, respectively, and the thermal and electric load values are denoted $B$ and $B e q$, respectively. The corresponding coefficient matrix of the grey threshold can be used to present a variable range of the parameters. Set the corresponding whitened coefficients of Aeq and Beq as $a$ and $b$, Aeq $a \in[0,1]$ and $B e q \sim b \in[0,1][16]$. The whiting formulae are provided in (40) and (41). The whitened coefficient and corresponding coefficient are iteratively calculated. The algorithm for the flow of model substitution is shown in Figure 2.
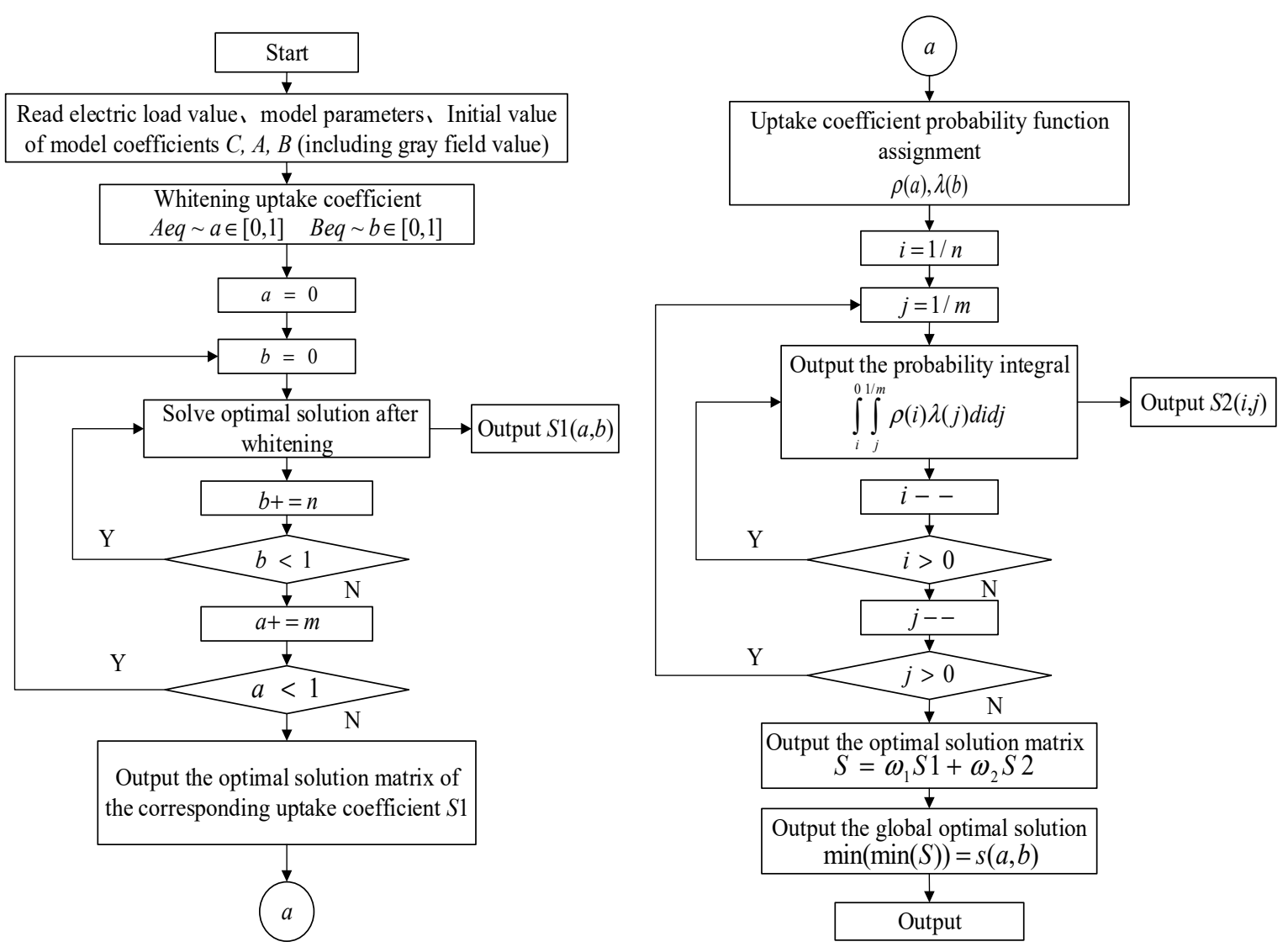

Figure 2. Economic operation using the grey multi-objective linear programming model. 
Step 1: Initialization. Whiten the optimal solution matrix. Whiten the probability integral matrix, which is a $[1 / n, 1 / m]$ order zero matrix. Obtain the technical parameters of the power generation and energy storage modules. Obtain the model constraint matrices $A$ and $A e q$, and the thermal and electric load values, and obtain the model constraint matrices $B$ and Beq. If the parameters are in the variable range, the corresponding coefficient matrix is represented by the corresponding grey field value.

Step 2: Whiten the grey coefficient in the model, and set the corresponding whitening uptake coefficients Aeq $\sim a \in[0,1]$ and Beq $\sim b \in[0,1]$ in the formulae from (40) and (41).

Step 3: Cycle the whitening uptake coefficient step by step to solve the optimal solution of multi-objective programming for the corresponding whitening uptake coefficient, and output the whitening optimal solution matrix $S 1$ at the end of the cycle.

Step 4: Using the grey multi-objective linear programming model of theorem 1 and theorem 2, for any point $\mathrm{A}$ and point $\mathrm{B}$ of the corresponding solution plane, if $0 \leq \mu_{a 1}<\mu_{a 2} \leq 1$ and $0 \leq \lambda_{b 2}<\lambda_{b 1} \leq 1$, then $S\left(\theta_{b 1}, \theta_{a 1}\right) \subset S\left(\theta_{b 2}, \theta_{a 2}\right)$. Therefore, the probability function is assigned to the whitening uptake coefficient, and the probability integral is solved to output the probability integral matrix.

Step 5: Weight the solution of the matrix to obtain the optimal solution for the probability integral that optimizes the global optimal solution under double constraints.

\section{Numerical Results}

\subsection{Example Analysis}

First, consider the grey multi-objective linear programming model of the objective function values, for the purposes of this example, of the standard time-sharing electricity charge for industrial enterprises according to the rules and relevant regulations of electricity prices in the power supply business, according to the transformer capacity (including highpressure motors without any transformer capacity) or the maximum demand. Large data on the $10 \mathrm{kv}$ industrial electricity prices from Liaoning province are shown in Table 1.

Table 1. $10 \mathrm{kv}$ Electricity price basic data questionnaire in Liaoning province.

\begin{tabular}{cccc}
\hline & - & $5: 00-7: 00$ & - \\
Time $(\mathrm{h})$ & $7: 00-12: 00$ & $12: 00-17: 00$ & - \\
& $17: 00-21: 00$ & $21: 00-22: 00$ & $22: 00-5: 00$ \\
Price $(\mathrm{RMB} / \mathrm{kWh})$ & 0.7482 & 0.4988 & 0.2494 \\
\hline
\end{tabular}

As the gas price is not fixed, the online query gas prices are set according to the data from 24 September 2021 based on the Shenyang gas price at 3.48 yuan/cubic meter.

The statistics for the constraint function in the model, including the environmental impact coefficient and equipment capacity configuration, are shown in Table 2 [17-19].

Table 2. Power generation unit environmental impact parameter table.

\begin{tabular}{ccc}
\hline Power Type & Pollution Coefficient $\mathbf{( g / k W h )}$ & Equipment Capacity (kW) \\
\hline Power grid & 889 & - \\
Wind turbines & 0 & 15 \\
PV cells & 0 & 28 \\
Micro gas turbine & 724.6 & 80 \\
\hline
\end{tabular}

Set the initial state of batteries as $\operatorname{SOC}\left(t_{0}\right)=K_{0}=1 / 30$, and set the initial state of thermal storage as $q_{s r}\left(t_{0}\right)=-10$. The micro gas turbine power supply constraint is [0,80], the grey threshold of the heating coefficient is [0.4, 0.6], the boiler system power supply constraint is [01, 20], and the grey threshold of the thermal storage's heat loss coefficient is $[0.7,0.7]$. The data for wind turbines, photovoltaic cells, heat load, and electric load have normal distributions within the scope of the threshold. Thus, the function for the corresponding whitened coefficient has a normal distribution. They can be initialized as 
$\lambda\left(b_{h}\right)=N(0.5 \quad 0.1), \lambda\left(b_{e}\right)=N(0.5 \quad 0.2)$, and $\lambda\left(b_{s}\right)=N(0.5 \quad 0.15)$. The grey domain of the power equipment's dissipative coefficient is the average distribution probability function. Select $m=n=0.02$, and run the simulation to calculate the model.

Use the grey multiple linear regression algorithms based on weather information to forecast the amount of energy generated by the wind turbines and PV battery. The forecasting result's error is under $10 \%$. Therefore, the constraint matrix of its grey domain can be set as $\pm 10 \%$ of the forecasting result, which is shown in Table 3 .

The result is as follows:

Table 3. Grey domain settings of $P_{w}, P_{s}, e_{\text {load }}, q_{h}$.

\begin{tabular}{|c|c|c|c|c|c|c|c|c|}
\hline Time (h) & $\underline{P}_{w}$ & $\bar{P}_{w}$ & $\underline{P}_{s}$ & $\bar{P}_{s}$ & $\underline{e}_{\text {load }}$ & $\overline{\boldsymbol{e}}_{\text {load }}$ & $\begin{array}{l}q \\
-h\end{array}$ & $\bar{q}_{h}$ \\
\hline 21 & 9.792 & 11.968 & 0.00 & 0.00 & 1.3 & 1.6 & 14.9 & 18.2 \\
\hline 22 & 12.672 & 15 & 0.00 & 0.00 & 2.5 & 3.1 & 14.9 & 18.2 \\
\hline 23 & 10.368 & 12.672 & 0.00 & 0.00 & 2.5 & 3.1 & 14.9 & 18.2 \\
\hline 24 & 11.52 & 14.08 & 0.00 & 0.00 & 2.1 & 2.5 & 14.5 & 17.7 \\
\hline 1 & 9.936 & 12.144 & 0.00 & 0.00 & 1.3 & 1.6 & 14.9 & 18.2 \\
\hline 2 & 10.656 & 13.024 & 0.00 & 0.00 & 1.3 & 1.6 & 14.9 & 18.2 \\
\hline 3 & 9.648 & 11.792 & 0.00 & 0.00 & 1.3 & 1.6 & 14.9 & 18.2 \\
\hline 4 & 11.952 & 14.608 & 0.00 & 0.00 & 1.3 & 1.6 & 14.9 & 18.2 \\
\hline 5 & 10.8 & 13.2 & 0.00 & 0.00 & 1.3 & 1.6 & 14.9 & 18.2 \\
\hline 6 & 8.352 & 10.208 & 0.45 & 0.55 & 2.5 & 3.1 & 14.9 & 18.2 \\
\hline 7 & 8.928 & 10.912 & 1.62 & 1.98 & 1.3 & 1.6 & 14.9 & 18.2 \\
\hline 8 & 7.344 & 8.976 & 3.15 & 3.85 & 1.3 & 1.6 & 39.3 & 48 \\
\hline 9 & 5.904 & 7.216 & 8.82 & 10.78 & 79.8 & 97.5 & 39.7 & 48.5 \\
\hline 10 & 7.2 & 8.8 & 12.15 & 14.85 & 188.0 & 229.8 & 36.9 & 45.1 \\
\hline 11 & 3.6288 & 4.4352 & 13.95 & 17.05 & 203.2 & 248.3 & 51.7 & 63.2 \\
\hline 12 & 2.88 & 3.52 & 18.36 & 22.44 & 166.9 & 204.0 & 75.2 & 92 \\
\hline 13 & 2.592 & 3.168 & 18.99 & 23.21 & 157.7 & 192.8 & 63.2 & 77.2 \\
\hline 14 & 3.744 & 4.576 & 19.62 & 23.98 & 201.9 & 246.8 & 57.1 & 69.8 \\
\hline 15 & 2.448 & 2.992 & 16.11 & 19.69 & 206.6 & 252.6 & 70.8 & 86.6 \\
\hline 16 & 3.6 & 4.4 & 9.99 & 12.21 & 216.0 & 264.0 & 47.2 & 57.7 \\
\hline 17 & 4.752 & 5.808 & 6.03 & 7.37 & 140.4 & 171.5 & 52.9 & 64.6 \\
\hline 18 & 6.912 & 8.448 & 0.45 & 0.55 & 83.0 & 101.4 & 38 & 46.5 \\
\hline 19 & 8.784 & 10.736 & 0.00 & 0.00 & 167.6 & 204.8 & 28.6 & 34.9 \\
\hline 20 & 10.656 & 13.024 & 0.00 & 0.00 & 161.9 & 197.8 & 16.1 & 19.6 \\
\hline
\end{tabular}

Due to the industrial enterprises' load being of a single wave form, during 21-24 PM, the load is in the low range, so the energy storage unit during this time period cannot self-prepare for the next $24 \mathrm{~h}$ and loses part of its energy storage function. Therefore, in order to achieve maximum energy-saving effects, the optimization time period is adjusted forward by $4 \mathrm{~h}$. In order to conveniently read the results shown below, other than the energy storage equipment, the result is still shown with the $x$-axis starting at zero.

\subsection{Simulation Result}

First, in the condition $m=n=0.02$, the optimal solution matrix of the whitened values and the corresponding probability distribution value of the whitened coefficient can be calculated, as shown three-dimensionally in Figure 3. 


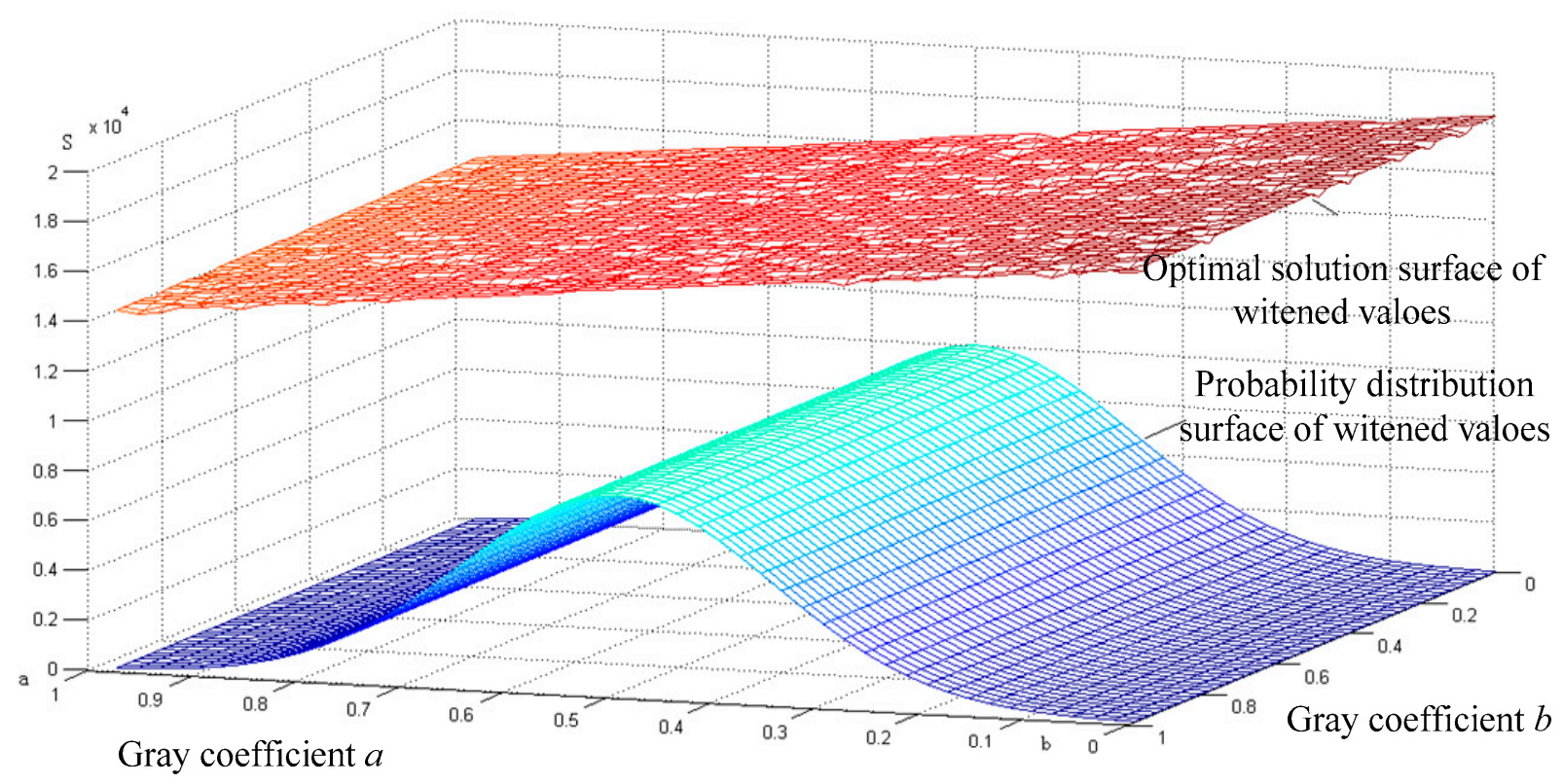

Figure 3. Economic operation flowchart for the grey multi-objective linear programming model.

The range of corresponding whitening constraint values $a$ and $b$ for the $x$ - and $y$-axes is $[0,1], \mu_{\alpha}=0.02$, and $\lambda\left(b_{h}\right)=N(0.5 \quad 0.1)$, integrating $\int_{i}^{0} \int_{j}^{50} \mu(i) \lambda(j) d i d j$. Then, the integral results and the optimal whitened solution are weighted by sum, and the results obtained are shown in Figure 4.

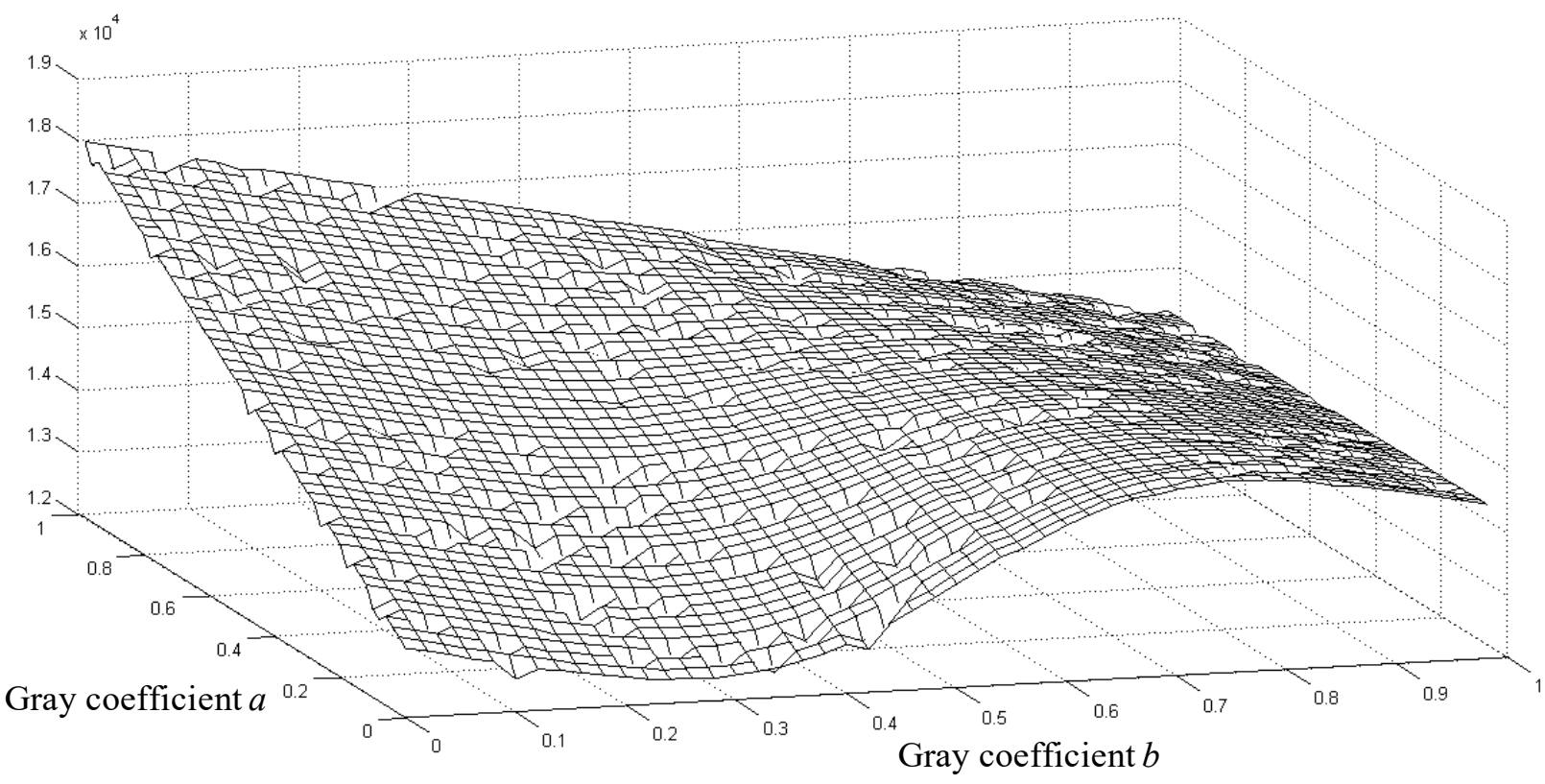

Figure 4. Grey multi-objective programming the global optimal solution surface.

To achieve the optimal solution after comprehensive consideration, the objective functions need to be as economical as possible while meeting most energy constraints. The optimal solution of the resulting surface is shown in Figure 5. The optimal solution of the probability integral is $85.44 \%$, and the corresponding points are $S(0.02,0.34)=0.02$. However, that point and the optimal solution value do not have physical meanings. The plan with all equipment running is shown as follows, and the electrical load requirements and their grey domain values are shown in Figure 5. 


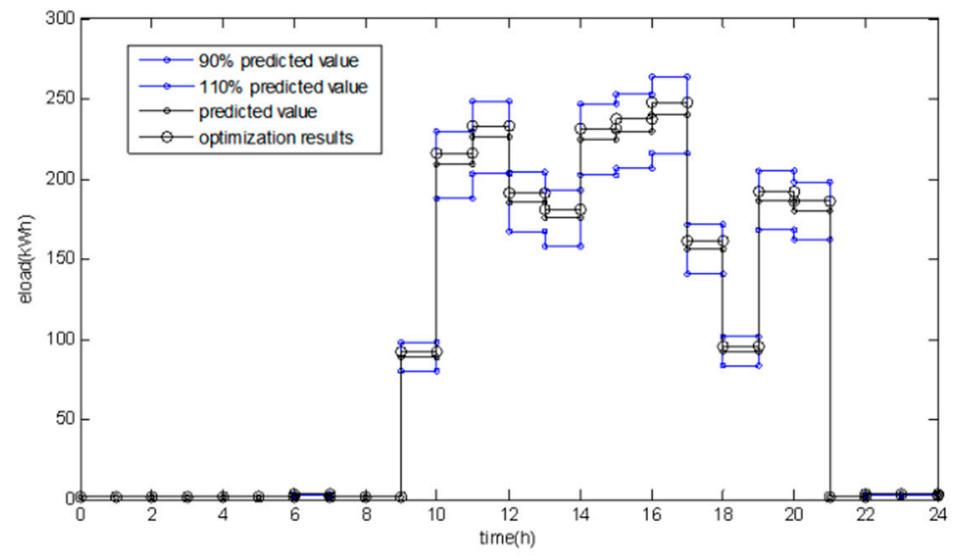

Figure 5. Electrical load requirements and their grey domain values.

Figure 6 shows an electricity supply plan for microgrid power. When the electric load is low, the period of the energy generated by wind power is high and the storage battery is charged to full capacity in preparation for a peak load. Due to the microgrid coordinating energy, a significant peak sharpening effect is seen, where $48 \%$ of the peak electricity is provided by the microgrid and $50 \%$ of the flat electricity is provided by other distributed units of the system.

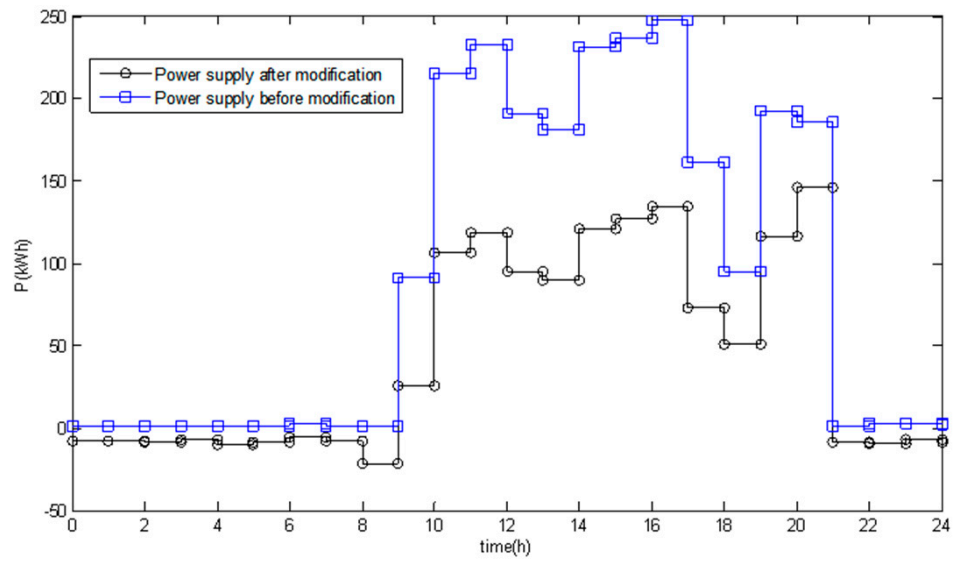

Figure 6. Output power of the grid.

The output power of the wind turbines and their grey domain values are shown in Figure 7.

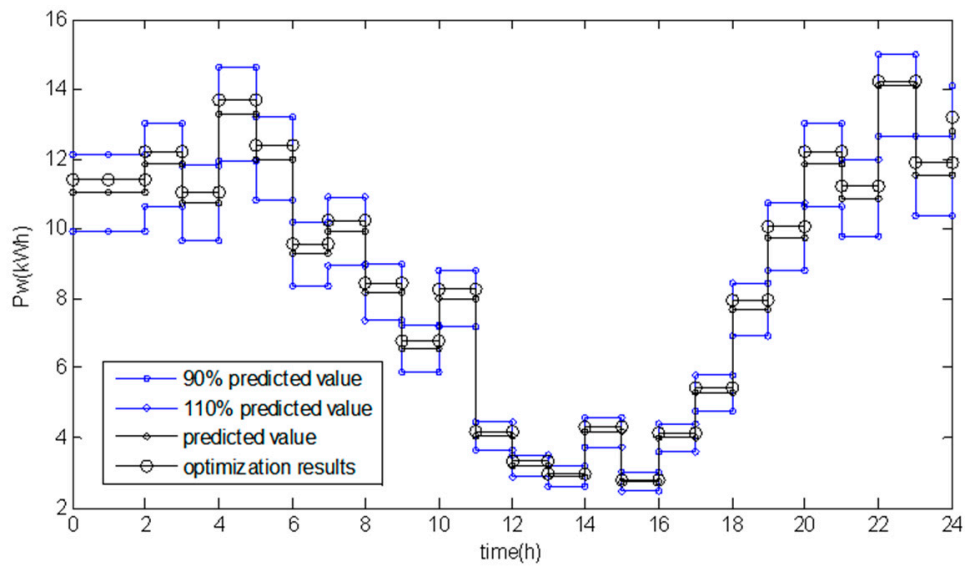

Figure 7. Output power of the wind turbines and their grey domain values. 
The output power of the photovoltaic cells and their grey domain values are shown in Figure 8 .

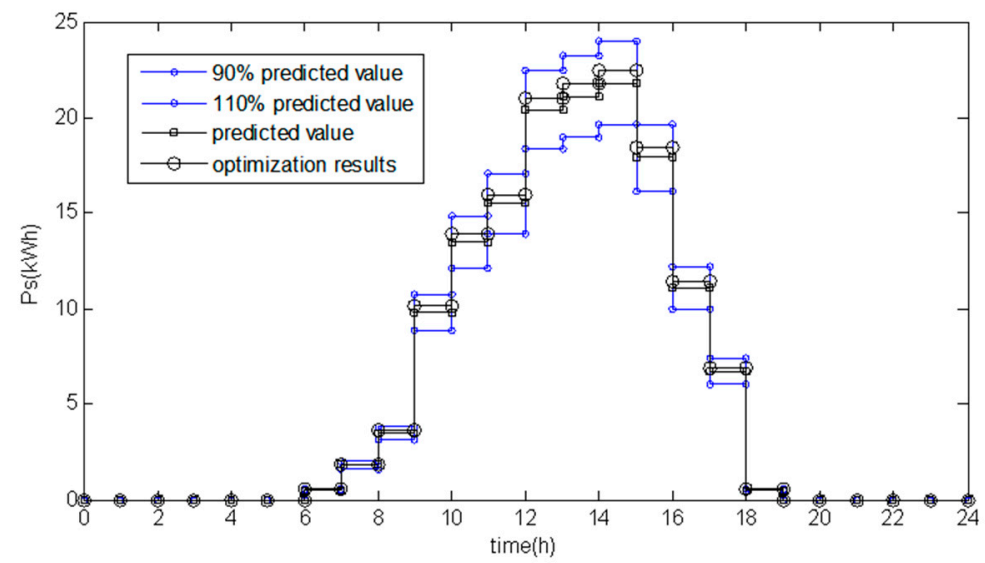

Figure 8. Output power of the photovoltaic cells and their grey domain values.

Figure 9 presents the micro gas turbine electricity supply plan, and the micro gas turbine's main power period is the peak load period for electricity and heat, all while running under maximum capacity. During this period, the cost of using power generated by the gas turbine is lower than that from the power grid. Thus, the gas turbine helps supply heat energy.

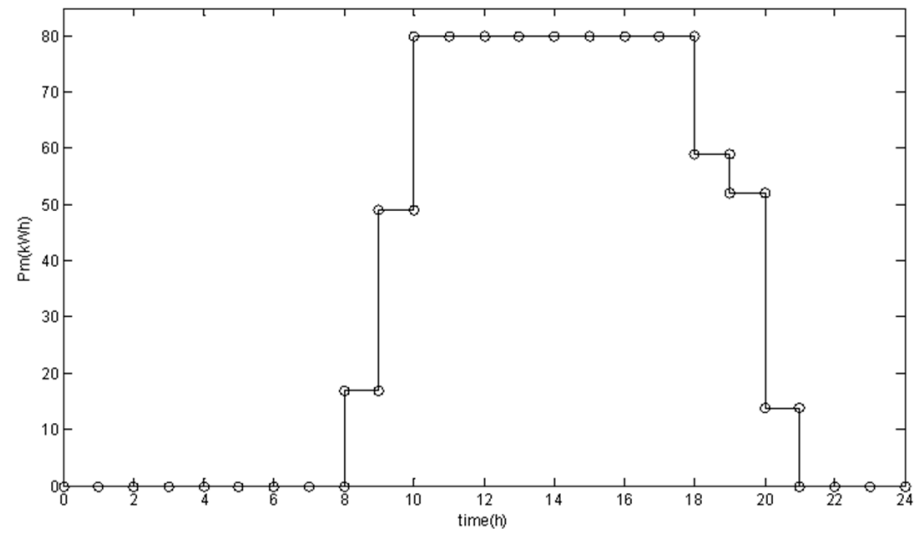

Figure 9. Output power of the micro-turbines.

Figure 10 shows the performance of the battery system, with the negative part indicating that the battery is in a charged state and the positive part indicating that the battery is in a discharged state. As seen, at 09:00, 10:00, 13:00, and other times when battery energy is required, the battery is in a discharged state, and the discharged power reaches a peak suppression effect when the battery reaches its peak, while the battery is in a charged or idle state during the remaining time.

Of note, the SOC of the battery is measured at the initial moment of each time period, so the SOC of each time period is determined according to the charge and discharge of the battery from the previous time. In contrast, the positive part of the black curve indicates that the battery is in a charged state while the negative part indicates that the battery is in a discharged state.

The SOC of the battery is shown in Figure 11. 


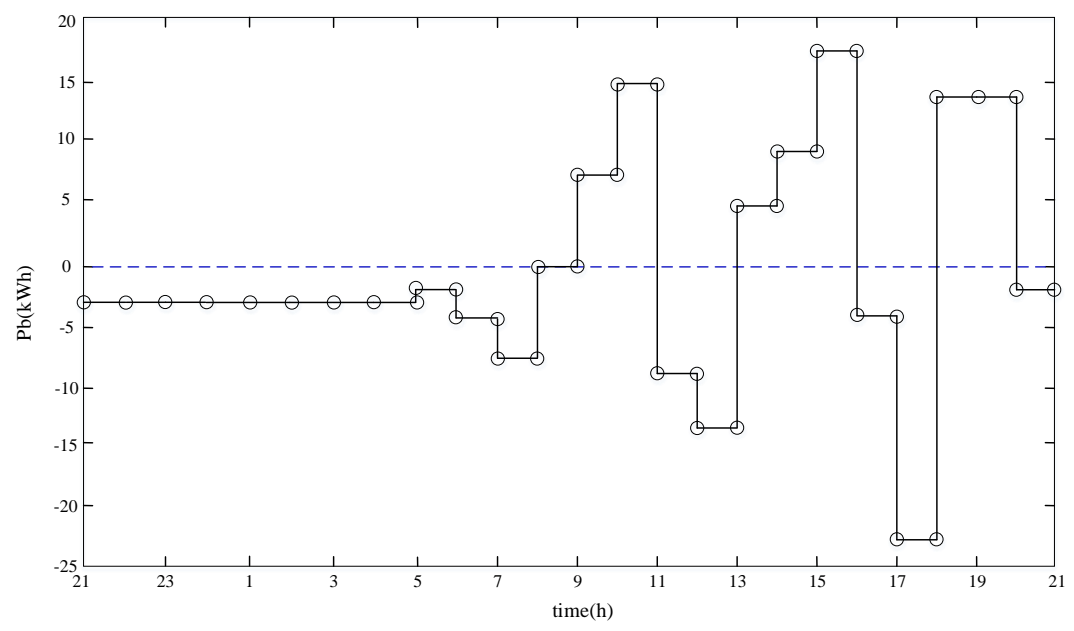

Figure 10. Output or input power of the battery.

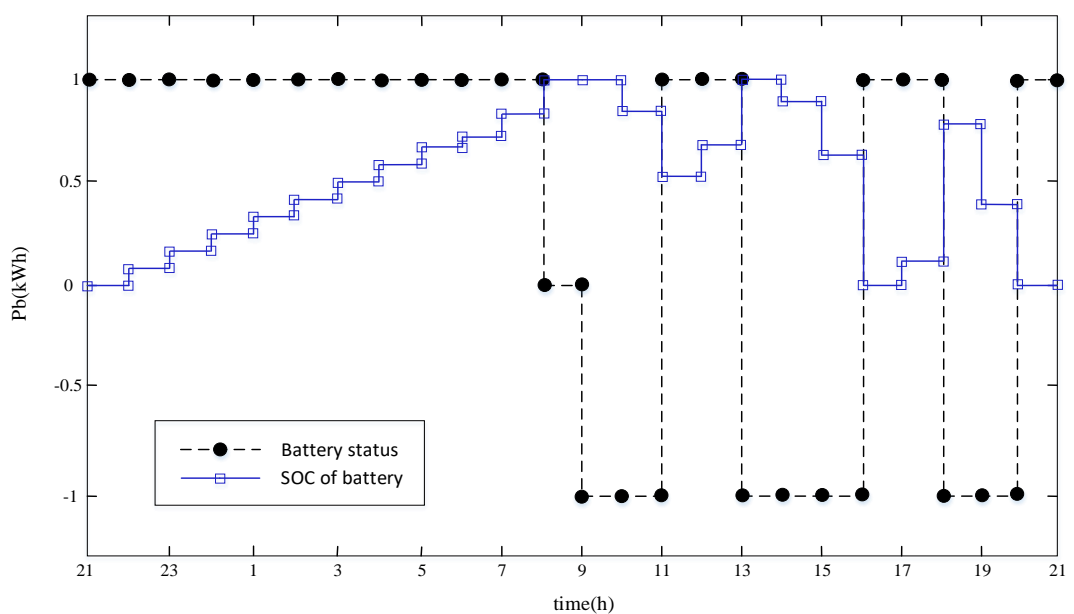

Figure 11. The $S O C$ of the battery.

The heat load requirements and their grey domain values are shown in Figure 12.

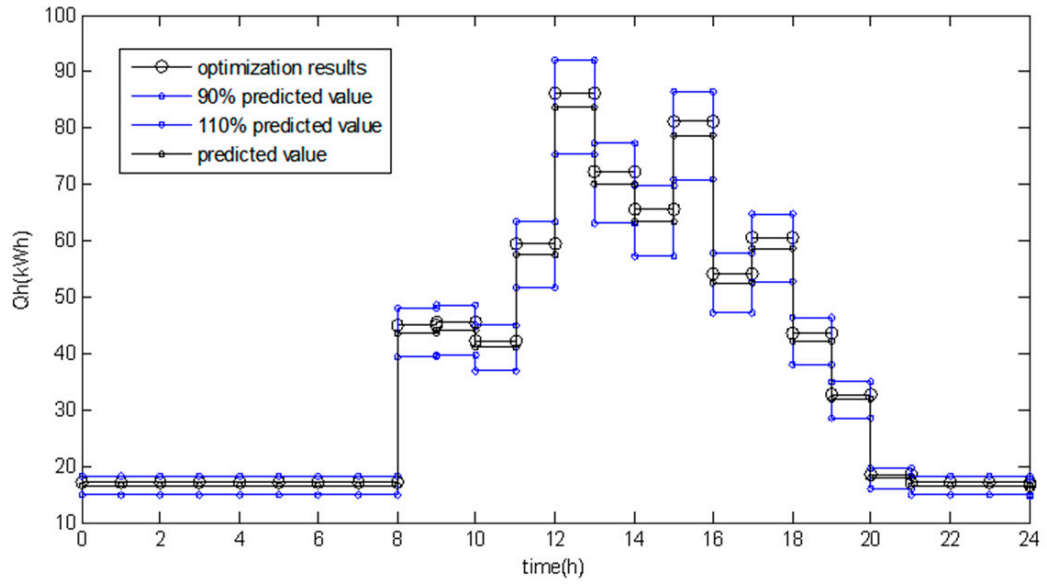

Figure 12. Heat load requirements and their grey domain values.

Figure 13 shows the heat supply plan for the heating boiler system. The duration of heat supplied is $24 \mathrm{~h}$ a day and it is a little higher during the peak period, while no big fluctuations occur. 


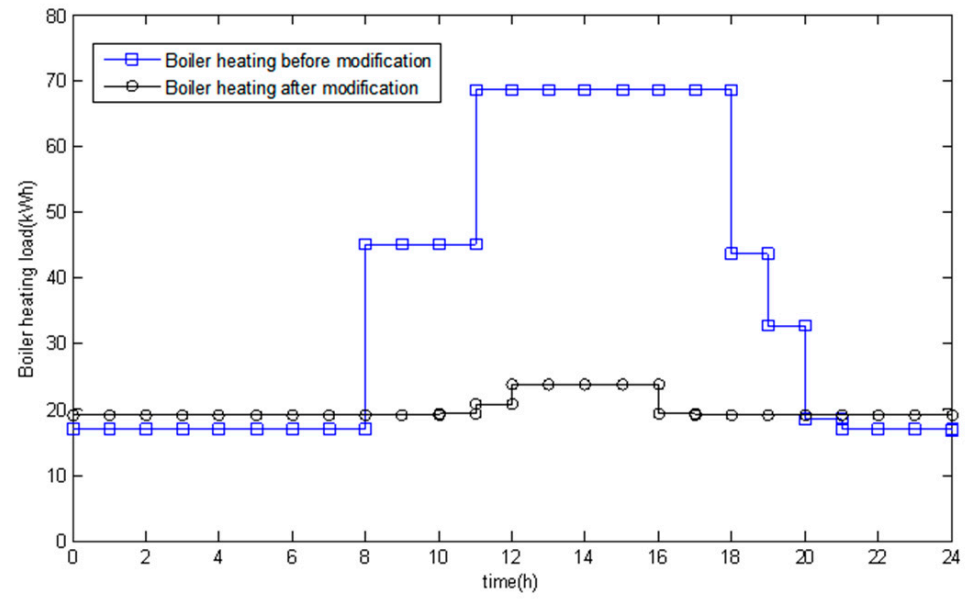

Figure 13. Output heat of the electric heating boiler.

Figure 14 shows the micro gas turbine for the system that provides heat, and the heating load for the grey value is shown in the figure by applying the global optimal to the heating load and by using the visible micro gas turbine as the main heat source.

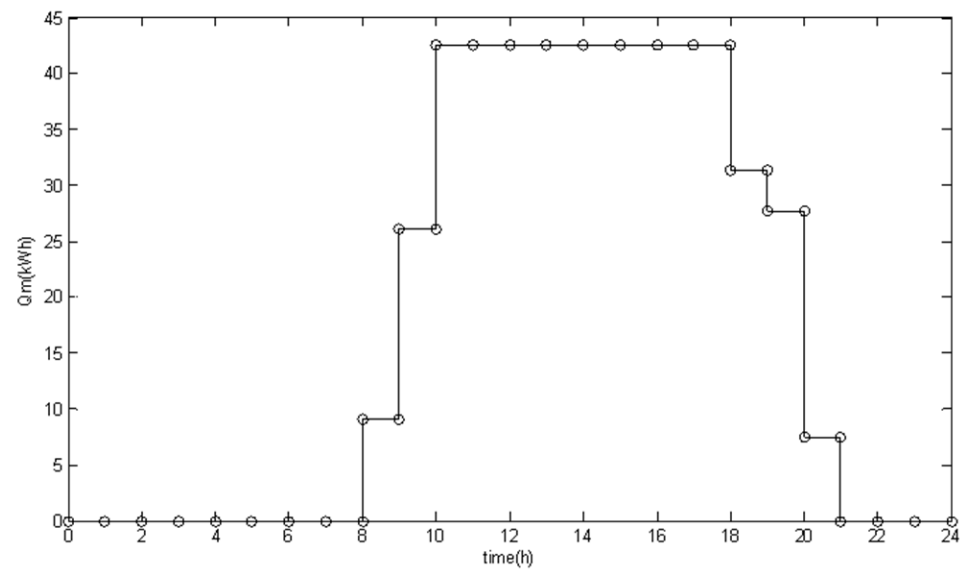

Figure 14. Output heat of the micro-turbines.

In Figure 15, the heat supply plan of the thermal storage system can be seen in the hot trough period in the heat storage condition. When run, it instantaneously releases heat, and during the day, it charges and discharges energy many times.

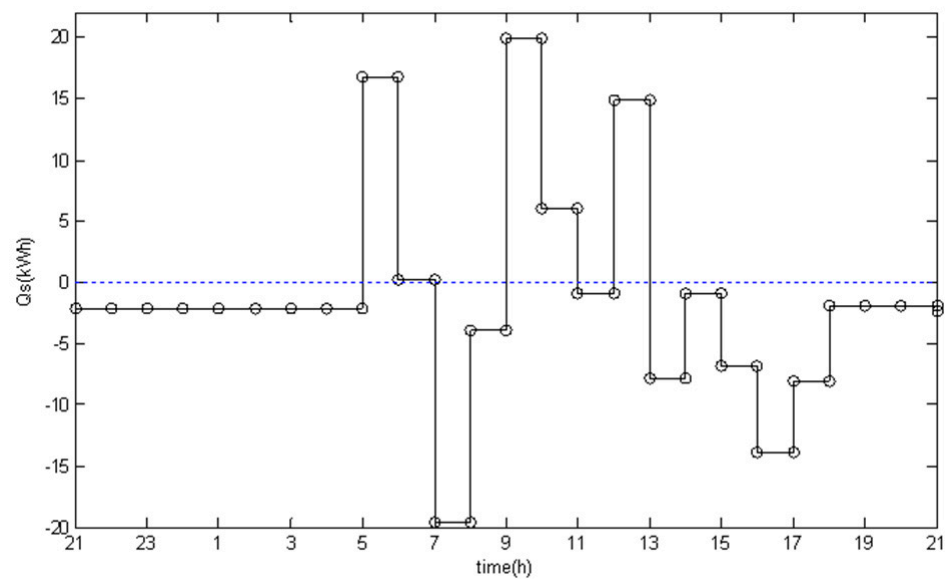

Figure 15. Output heat of the thermal storage. 
The remaining heat in thermal storage is shown in Figure 16.

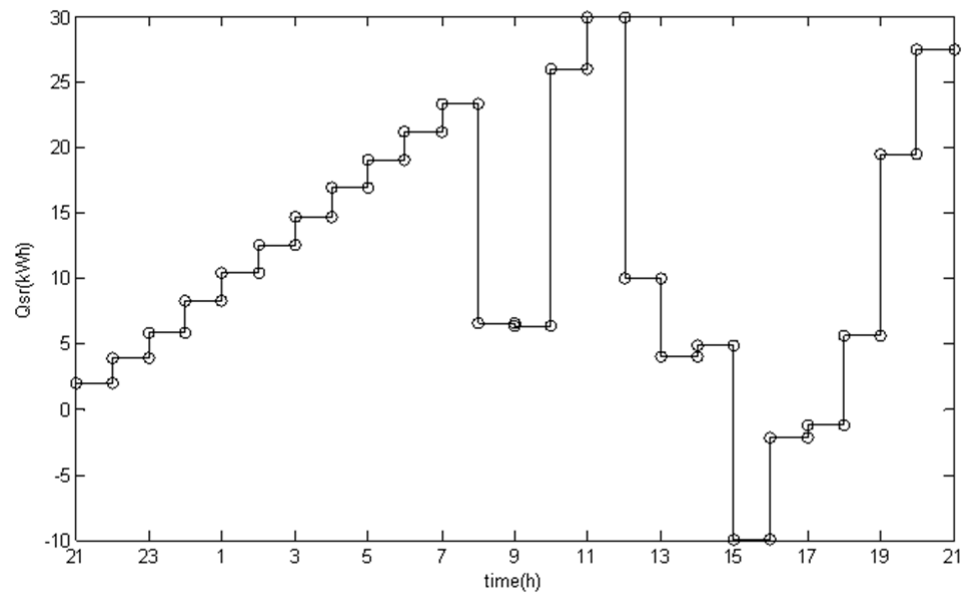

Figure 16. The remaining heat in thermal storage.

Considering the corresponding equipment for energy supply and demand relations, and each period when the main equipment supplies the load power, a detailed analysis of the electricity supply and demand relationship is shown in Figure 17 and a detailed analysis of the heat supply and demand relationship is shown in Figure 18.

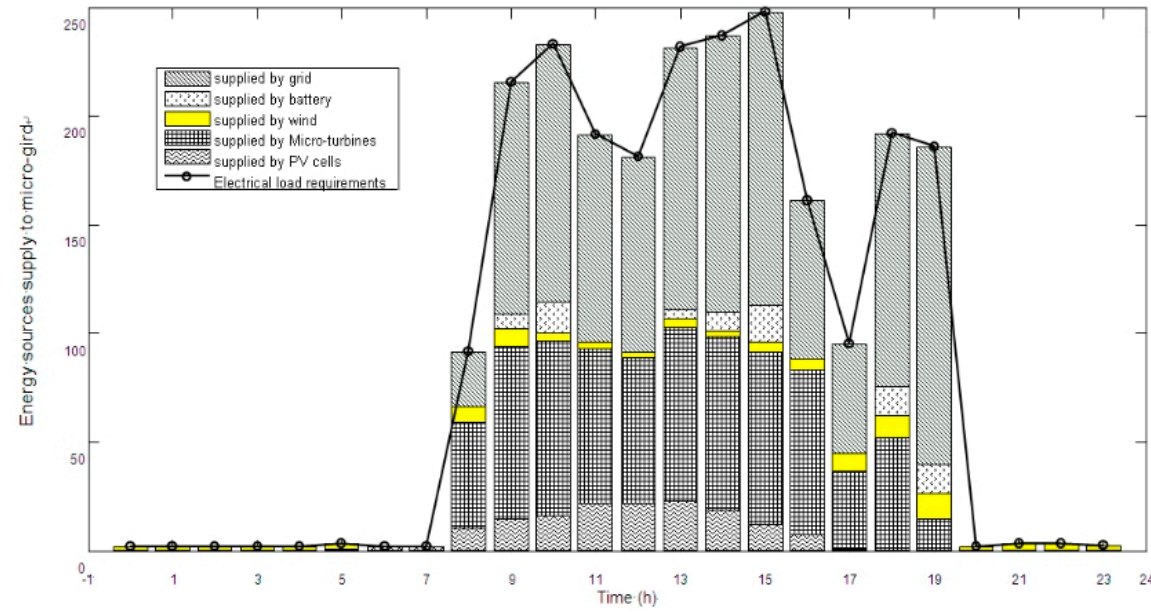

Figure 17. Composition of the electrical energy supplies.

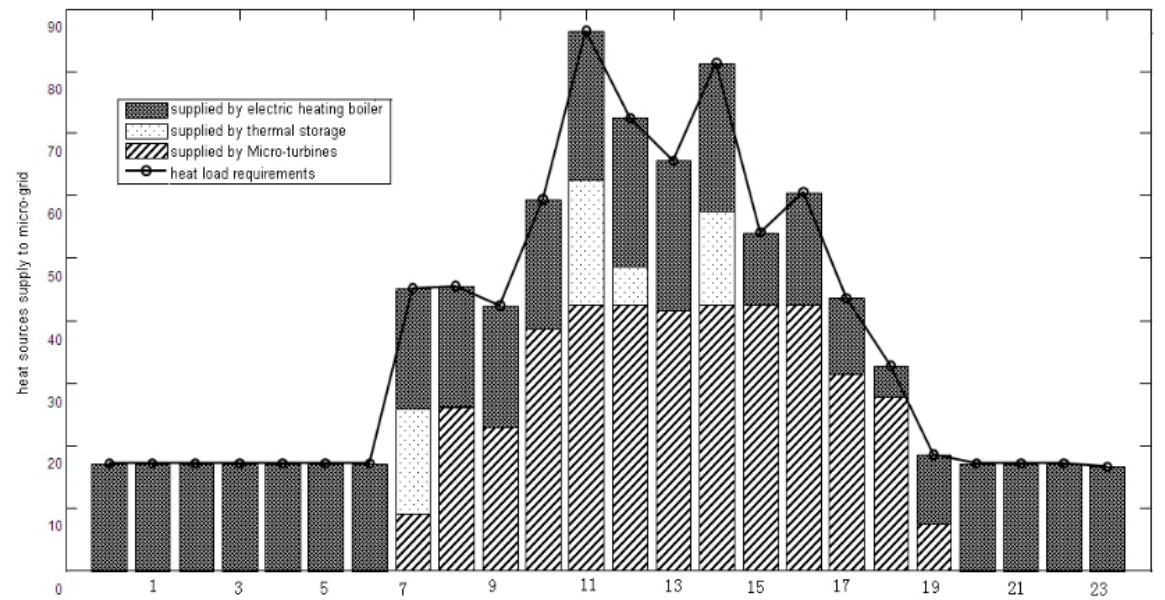

Figure 18. Composition of the heat energy supplies. 
In Figure 17, the system load includes electricity used for lighting, ventilation, office buildings, and air conditioning; electricity production; and electricity from the electric heating boiler. The supply of electricity is from the grid, a miniature gas turbine, wind turbines, photovoltaic cells, as well as the battery. During 20:00-7:00, which is a trough in the electricity load period, the power is mainly provided by wind turbines, while during 8:00-19:00, which is the peak load period, power is mainly provided by the power grid and a gas turbine. Compared with the single-energy-source supply plan, the battery plays a very important role in coordinating energy.

As seen in Figure 18, thermal storage plays an important role in coordinating heat. During 20:00-6:00, the electric heating boiler is the only heat supply source. During 7:00-19:00, which is the peak heat load period, the heat load is mainly provided by the gas turbine, the electric boiler, and thermal storage. Therefore, the gas turbine supplies the majority of heat during the peak hot load period. The use of thermal storage avoids frequent alterations in the gas turbine and electric boiler, which can increase the heating efficiency and the service life of the equipment.

The running results of two optimization algorithms and the algorithm without distributed energy resource and optimization are shown in Figure 19. From these results, the calculated results are shown as being able to optimize the system. Since methods have advanced and the economic costs of this method are discussed, a comparison and an analysis of various kinds of optimization methods are shown in Table 4.

In common multiple linear regression algorithms, there are multiple objective functions and certain contradictions between objectives. In the case, there is no optimal solution of the usual meaning. The solution of the multi-objective planning problem can be divided into three situations: (1) If at least one solution enables all the objectives of the multiobjective planning problem to be achieved, the solution is called the optimal solution for the multi-objective planning; (2) If at least one solution can only meet part of the importance objectives in the multi-objective planning problem, the solution is called a suboptimal or feasible solution for multi-objective planning; (3) If solution that can meet any goal of the multi-target planning problem cannot be found, then the multi-target planning problem has no solution. At this time, it is shown that the existing constraints of the multi-target planning problem are contradictory, and reasonable and feasible goals need to be reset for solution.

Without distributed energy resource and optimization

Common multiple linear regression algorithms

Grey multiple linear regression optimization algorithms

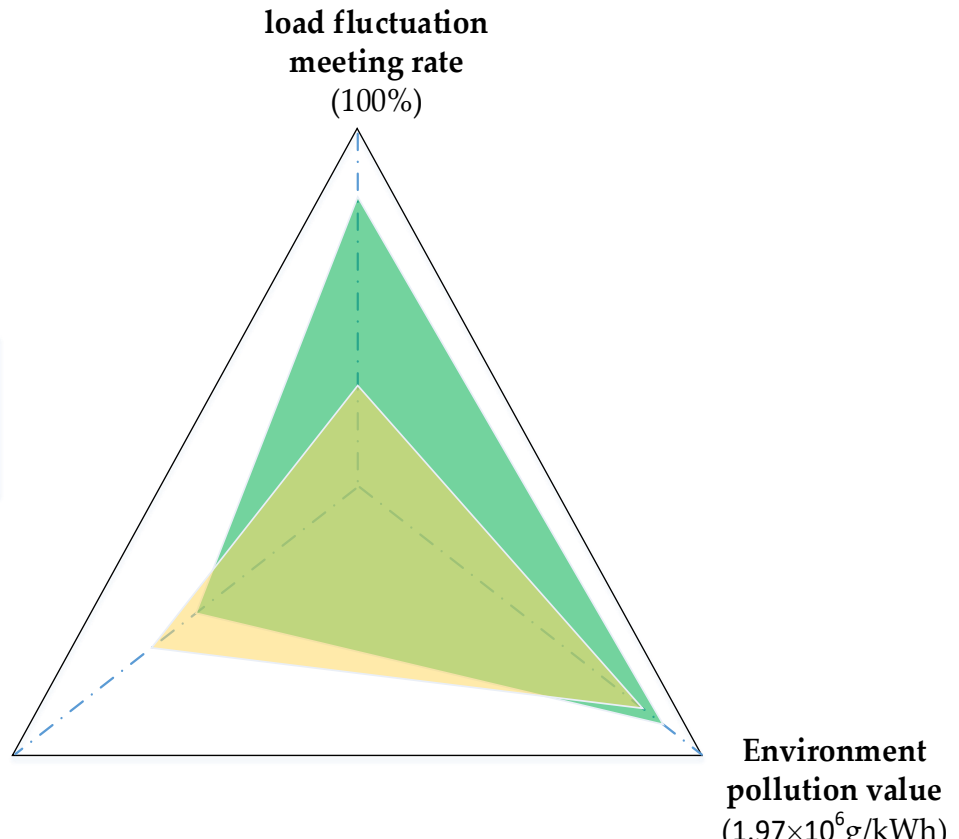

$(223.6$ \$)

$\left(1.97 \times 10^{6} \mathrm{~g} / \mathrm{kWh}\right)$

Figure 19. The running results of three algorithms. 
Table 4. A comparison of the performances of different methods.

\begin{tabular}{lccc}
\hline Optimization Method & $\begin{array}{c}\text { load Fluctuation } \\
\text { Meeting Rate }\end{array}$ & Total Cost (\$) & $\begin{array}{c}\text { Environment Pollution } \\
\text { Value (g/kWh) }\end{array}$ \\
\hline Without distributed energy resource and optimization & $100 \%$ & 223.6 & $1.97 \times 10^{6}$ \\
\hline Common multiple linear regression algorithms & $25 \%$ & 187.3 & $1.6 \times 10^{6}$ \\
\hline Grey multiple linear regression optimization algorithms & $87 \%$ & 173.3 & $1.7 \times 10^{6}$ \\
\hline
\end{tabular}

There are many solutions for common multiple linear regression algorithms, such as the ideal point method, sum of square weighting method, linear weighting method, priority method, minimum maximum method, etc. This paper takes the priority method as the solution method of the common multiple linear regression algorithms. The basic idea of the method is to divide into different priorities according to the importance between different targets. First seeking the optimal value of the high priority objective function, on the premise of ensuring that the high priority target, and then seeking the optimal value of the low priority target function, the optimal solution is the multi-objective planning problem (satisfactory solution).

From Table 4, forecasting the cost for one day as an example, when the system has no distributed energy resource and optimization, the total energy consumption cost is 223.6 USD, the environment pollution value is $1.97 \times 10^{6}$, and the total cost of a day has a lot of room for improvement.

Using common multi-objective linear programming algorithms, because new energy resources are replacing the traditional power grid, the total cost is reduced by a lot and environmental pollution is also greatly reduced. However, for system uncertainty, this method is useful when the load of the system is low. Therefore, the method is adopted.

Using the proposed grey multi-objective linear regression optimization algorithms to obtain the global optimal solution, the new total cost is 27.1 USD, in which electricity makes up 120.9 USD, the gas fee is 58.6 USD, and the environment pollution value is $1.7 \times 10^{6}$, compared with the cost when optimization is not used, 223.6 USD; the amount of savings from daily optimization, 50.3 USD; and the reduction in environmental pollution, $2.7 \times 10^{5}$.

The optimization results in Table 4 mainly reflect the constraints between energy supply and demand. The optimization results are not only affected by the energy supply and demand, but also by the time-sharing electricity price. The rise in electricity price will increase the total cost of power grid operation, but after optimizing the system with a gray multi-target linear planning method, the cost-saving cost will increase. This is due to the optimized system, and its utilization rate of electricity is greatly improved, thus saving more power. The electric energy saved is calculated into the cost saving according to the electricity price at this time, which will ultimately increase the cost saving.

In order to highlight the characteristics of the method used in this paper, we compared the results with those from recent literature. Taking Reference [20] as an example, the following parts are included in the comparison:

This paper proposes a distributed distribution feeder load management method based on an autonomous decision-making entity that not only relieves the system pressure, but also ensures customer satisfaction by optimizing the demand constraint limit to alleviate the demand rebound effect. Compared with the results of a method based on the water injection algorithm and the simple and fair distribution method, the method designed is verified as having a more efficient performance in alleviating demand rebound and in reducing transformer congestion.

However, in order to meet the requirements of the model solution or to facilitate calculation, the equipment parameters and load prediction data involved in the above article are regarded as ideal data, but this does not reflect reality. As can be seen from the optimization results of this paper, the changes in parameters and load requirements greatly affect the final optimization results. Therefore, the grey multi-target linear planning algo- 
rithm proposed in this paper can obtain relatively global optimal results when considering uncertainties or uncertain parameters in an actual situation.

In the process of optimizing the operation of a multi-energy microgrid in this paper, the corresponding energy management was conducted from the perspective of the economy and exhaust emissions. At the same time, based on relevant data from actual industrial enterprises, a multi-energy microgrid model integrating wind power, photoelectric power, an energy storage system, and a gas system is established, and the optimized constraint function and control target of a multi-energy microgrid are determined, which is more in line with the actual situation in a multi-energy microgrid.

\section{Conclusions}

In this paper, the management of a multiple energy system in the manufacturing industry is considered and balancing the optimization of optimal economic goals, optimal environmental targets, and use of optimal equipment is attempted. First, the scheduling problem is formulated as multiple linear regression algorithms. Second, grey theory is applied to the formulation to solve uncertainty factors. Third, improved grey multiple linear regression optimization algorithms are applied to optimize all of the power supply devices and energy storage equipment. Note that the scheduling problem is continuously solved and that only the equipment's capacity is implemented. This could be affected by adjusting the device's capacity, especially the storage device.

The following points are summaries of the innovations in this study:

(1) Combining wind power, photoelectric power, an energy storage system, and a gas system, the energy management system is designed focused on the economy and on greenhouse gas emissions. Considering the actual operation of a multi-energy microgrid system, in order to make the energy management scheme more practical, a variety of optimization objectives and constraints are proposed in this paper. The optimization objectives and constraints are determined not only by taking into account the economic cost of micro-network operations, but also by mathematically modeling the exhaust emissions when the system is run and by setting the corresponding energy control targets in terms of economic benefits and environmental protection.

(2) For the possible uncertainty resulting when constructing the multi-objective model and the constraints in practical engineering cases, the grey multi-objective linear planning algorithm is proposed. Using the grey multi-target linear planning algorithm, the multi-target multi-energy optimization management of a microgrid is realized. By comparisons with multiple optimization methods, the economic costs of the proposed method are verified and the amount of cost savings and the cost recovered using our method are analyzed. The verification results meet the optimized operating conditions of a multi-energy microgrid system after analysis.

The method proposed in this paper can realize the optimal operation of multi-energy microgrid systems, but some shortcomings are also present. The focus of the optimal operation of the multi-energy microgrid system proposed in this paper is on small and medium-sized industrial enterprises. Due to their own electric load and thermal load characteristics, a typical winter day is used as the data source for the load samples. This paper did not consider the use of a cooling load in high temperatures during summer, but considering recent trends in global warming, with the temperature increasing in summer, even industrial enterprises need to be equipped with corresponding refrigeration equipment to ensure that production activities progress as usual. Therefore, in a follow-up research, we should consider the impact of a summer cooling load on the optimal operation of a multi-energy microgrid system and should increase the accuracy and reliability of the microgrid optimization operation.

At the same time, the methods proposed in this paper are based on theoretical research and the focus is also limited to the power load, with obvious peak and trough periods for industrial enterprises. Certain practical engineering cases are also lacking to verify the practicability of our methods. In the future, further development of the software is needed 
to apply it to an actual energy efficiency management system, to constantly improve the flexibility and accuracy of the algorithm, and finally to invest in complex microgrids with various types of loads to contribute to green energy savings.

Author Contributions: Conceptualization, B.H. and N.W.; methodology, Z.Y.; software, Y.C.; validation, N.W.; formal analysis, Z.Y.; investigation, B.H.; resources, B.H.; data curation, N.W.; writingoriginal draft preparation, B.H.; writing — review and editing, N.W.; visualization, N.W.; supervision, B.H.; project administration, L.S.; funding acquisition, D.Y. and Y.C. All authors have read and agreed to the published version of the manuscript.

Funding: This research was supported by the National Natural Science Foundation of China (U1908217, 61704148), the Liaoning Revitalization Talents Program (XLYC1902090), National Key Research and Development Project (2018YFB1700500), the Fundamental Research Funds for the Central Universities (N180415004) and Natural Science Foundation of Jiangsu Province (BK20170514).

Institutional Review Board Statement: Not applicable.

Informed Consent Statement: Not applicable.

Data Availability Statement: The data used to support the findings of this study are available from the corresponding authors upon request.

Conflicts of Interest: The authors declare no conflict of interest.

\section{Nomenclature}

\begin{tabular}{|c|c|}
\hline$C_{t}^{p}$ & Total cost of electricity during $t$ (USD). \\
\hline$C_{t}^{n}$ & Total cost of natural gas during $t$ (USD). \\
\hline$p(t)$ & Power from the grid during $t(\mathrm{kw})$ \\
\hline$p_{\text {res }}(t)$ & Clean power generation during $t(\mathrm{kWh})$ \\
\hline$v(t)$ & Natural gas consumption during $t\left(\mathrm{~m}^{3}\right)$ \\
\hline$c_{p}^{d}(t)$ & Buying price of electricity during $t$ (USD/kWh) \\
\hline$c_{p}^{u}(t)$ & Selling price of electricity during $t$ (USD/kWh). \\
\hline$c_{p}^{r} p(t)$ & Spontaneous self-used subsidy electricity price of electricity during $t$ (USD/kWh). \\
\hline$c_{n}(t)$ & Natural gas price of electricity during $t$ (USD/kWh) \\
\hline$\tau$ & Time interval \\
\hline$S_{t}^{p}$ & Exhaust gas amount produced by using electricity during $t$ \\
\hline$s_{S O}^{p}(t)$ & Exhaust $\mathrm{SO}_{\mathrm{X}}$ amount produced by using electricity during $t$ \\
\hline$s_{n o}^{p}(t)$ & Exhaust $\mathrm{NO}_{X}$ amount produced by using electricity during $t$ \\
\hline$s_{c o}^{p}$ & Exhaust $\mathrm{CO}_{2}$ amount produced by using electricity during $t$ \\
\hline$s_{s o}^{n}(t)$ & Exhaust $\mathrm{SO}_{\mathrm{X}}$ amount produced by using gas turbines during $t$ \\
\hline$s_{n o}^{n}(t)$ & Exhaust $\mathrm{NO}_{\mathrm{X}}$ amount produced by using gas turbines during $t$ \\
\hline$s_{c o}^{n}$ & Exhaust $\mathrm{CO}_{2}$ amount produced by using gas turbines during $t$ \\
\hline$s_{S o}^{m}(t)$ & Exhaust $\mathrm{SO}_{X}$ amount produced by using gas fired boiler during $t$ \\
\hline$s_{n o}^{m}(t)$ & Exhaust $\mathrm{NO}_{X}$ amount produced by using gas fired boiler during $t$ \\
\hline$s_{c o}^{m}$ & Exhaust $\mathrm{CO}_{2}$ amount produced by using gas fired boiler during $t$ \\
\hline$c_{b p}$ & Maintenance cost of the battery (USD) \\
\hline$c_{p v p}$ & Maintenance cost of the photovoltaic cells (USD) \\
\hline$c_{w p}$ & Maintenance cost of the wind turbines (USD) \\
\hline$c_{E B P}$ & Maintenance cost of the electric boiler (USD) \\
\hline$c_{m p}$ & Maintenance cost of the micro gas turbines (USD) \\
\hline$c_{n p}$ & Maintenance cost of the micro gas fired boiler (USD) \\
\hline$c_{S}$ & Maintenance cost of the heat accumulator (USD) \\
\hline$e_{\text {load }}(t)$ & Total electricity load demand during $t(\mathrm{kWh})$ \\
\hline$p_{s}(t)$ & Electricity provided by the photovoltaic cells during $t(\mathrm{kWh})$ \\
\hline$p_{w}(t)$ & Electricity provided by the wind turbines during $t(\mathrm{kWh})$ \\
\hline$p_{m}(t)$ & Electricity provided by the micro gas turbines during $t(\mathrm{kWh})$ \\
\hline$p_{b}(t)$ & Electricity provided by the battery during $t(\mathrm{kWh})$, charge $(>0)$ or discharge $(<0)$ \\
\hline$q_{h}(t)$ & Total heat demand during $t(\mathrm{kWh})$. \\
\hline
\end{tabular}




\begin{tabular}{|c|c|}
\hline$q_{E B}(t)$ & Heat provided by the electric boiler during $t(\mathrm{kWh})$ \\
\hline$q_{E D}(t)$ & Heat provided by the gas fired boiler during $t(\mathrm{kWh})$ \\
\hline$q_{s}(t)$ & Heat provided by the heat accumulator during $t(\mathrm{kWh})$ \\
\hline$q_{m}(t)$ & Heat provided by the micro gas turbines during $t(\mathrm{kWh})$ \\
\hline $\mathrm{COPH}(t)$ & Heat converse rate of the heat accumulator during $t$ \\
\hline $\operatorname{COPM}(t)$ & Heat converse rate of the micro gas turbines during $t$ \\
\hline $\operatorname{COP}(t)$ & Heat converse rate of the electric boiler during $t$ \\
\hline $\operatorname{COD}(t)$ & Heat converse rate of the electric boiler during $t$ \\
\hline$z_{b}^{c}(t)$ & Discrete variable, " 1 " for the battery charging during $t$, “ 0 ," otherwise. \\
\hline$z_{b}^{d}(t)$ & Discrete variable, " 1 " for the battery discharging during $t$, , 0 ," otherwise. \\
\hline$z_{m p}(t)$ & Discrete variable, " 1 " for the micro gas turbines running during $t, " 0$, , otherwise. \\
\hline$z_{S}^{c}$ & Discrete variable, " 1 " for the heat accumulator charging during $t$, " 0 ," otherwise. \\
\hline$z_{s}^{d}$ & Discrete variable, " 1 " for the heat accumulator discharging during $t$, " 0 ," otherwise. \\
\hline$z_{E B}(t)$ & Discrete variable, " 1 ” for the electric boiler running during $t$, “ 0 ," otherwise. \\
\hline$z_{D E}(t)$ & Discrete variable, " 1 ” for the gas fired boiler running during $t$, , 0 ," otherwise. \\
\hline$z_{m}(t)$ & Discrete variable, " 1 " for the micro gas turbines running during $t$, " 0 ," otherwise. \\
\hline$g_{E D}(t)$ & Gas consumption of gas fired boiler \\
\hline$Q_{E B}$ & Rated power of the electric boiler $(\mathrm{kW})$ \\
\hline$Q_{E D}$ & Rated power of the gas fired boiler $(\mathrm{kW})$ \\
\hline$Q_{s}$ & Rated power of the heat accumulator $(\mathrm{kW})$ \\
\hline$q_{s r}(t)$ & Remaining heat energy in the heat accumulator device during $\mathrm{t}(\mathrm{kWh})$. \\
\hline$q_{s}(t)$ & Heat energy supplied by the heat accumulator device during $\mathrm{t}(\mathrm{kWh})$. \\
\hline$\underline{q}_{s i}$ & Minimal heat load rate of the heat accumulator $(\mathrm{kW})$ \\
\hline $\bar{q}_{s i}$ & Maximal heat load rate of the heat accumulator $(\mathrm{kW})$ \\
\hline$\underline{q}_{s o}$ & Minimal discharge rate of the battery $(\mathrm{kW})$ \\
\hline$\overline{\bar{q}}_{\text {so }}$ & Maximal discharge rate of the battery $(\mathrm{kW})$ \\
\hline & Electrical load ratio of the micro gas turbines during $t, x_{m}=p_{m} / p_{m}^{R}$ \\
\hline$p_{m}^{R}$ & Capacity of the micro gas turbines $(\mathrm{kWh})$ \\
\hline
\end{tabular}

\section{References}

1. Teng, Y.; Sun, P. Operation optimization model of micro-energy grid considering biomass waste classification and treatment. Autom. Electr. Power Syst. 2021, 45, 55-63.

2. Zhi, N.; Xiao, X.; Tian, P.G. Research status and prospect of microgrid group control technology. Electr. Power Autom. Equip. 2016, 36, 107-115.

3. Fan, Z.; Fan, B.; Peng, J.K. Operation Loss Minimization Targeted Distributed Optimal Control of DC Microgrids. IEEE Syst. J. 2020, 15, 5186-5196. [CrossRef]

4. Sang, B.; Zhang, T.; Liu, Y.J. Review on energy management system of multi-micro grid. Proc. CSEE 2020, 40, $3077-3093$.

5. Yin, L.J.; Zhao, X.L.; Mei, Z. Optimizing Technology for Micro Grid Operation Based on Chaos Particle Swarm Optimization Algorithm. Proc. CSU-EPSA 2016, 28, 55-61.

6. Chen, J.; Liu, Y.T.; Zhang, W. Analysis of optimal configuration of multistage microgrid in distribution network based on game theory. Proc. CSU-EPSA 2016, 40, 45-52.

7. Rokicki, Ł. Optimization of the Configuration and Operating States of Hybrid AC/DC Low Voltage Microgrid Using a Clonal Selection Algorithm with a Modified Hypermutation Operator. Energies 2021, 14, 6351. [CrossRef]

8. Riou, M.; Dupriez-Robin, F.; Grondin, D. Multi-Objective Optimization of Autonomous Microgrids with Reliability Consideration. Energies 2021, 14, 4466. [CrossRef]

9. Hu, C.; Luo, S.; Li, Z. Energy Coordinative Optimization of Wind-Storage-Load Microgrids Based on Short-Term Prediction. Energies 2015, 8, 1505-1528. [CrossRef]

10. Fatrias, D.; Alfadhlani; Kamil, I. Using grey-fuzzy programming approach to solve multi-objective supplier selection problem. In Proceedings of the 2017 4th International Conference on Industrial Engineering and Applications (ICIEA), Nagoya, Japan, 21-23 April 2017; Volume 4, pp. 141-145.

11. Wang, W.; Li, R.; Jiang, J.C. Key Issues and Research Prospects of Distribution System Planning Orienting to Energy Internet. High Volt. Eng. 2016, 42, 2028-2036.

12. Li, L.; Luo, Z.; He, F.; Sun, K.; Yan, X. An improved partial similitude method for dynamic characteristic of rotor systems based on Levenberg-Marquardt method. Mech. Syst. Signal Processing 2022, 165, 108405. [CrossRef]

13. He, L.J.; Li, W.F.; Zhang, Y. Application of Gray Relational Analysis in Optimization of Automotive Panel Forming. Control Decis. 2020, 35, 1134-1142.

14. Hu, Z.B.; Li, Z.; Dai, C.Y. Multiobjective Grey Prediction Evolution Algorithm for Environmental/Economic Dispatch Problem. IEEE Access 2020, 8, 84162-84176. [CrossRef] 
15. Zhao, H.; Guo, S.; Zhao, H. Selecting the Optimal Micro-Grid Planning Program Using a Novel Multi-Criteria Decision Making Model Based on Grey Cumulative Prospect Theory. Energies 2018, 11, 1840. [CrossRef]

16. He, X.H.; Yang, J.Y. Grey PSO algorithm-based multi-objective optimization of Scheduling of distributed power grid with peak load regulation. Journal of Lanzhou University of Technology. IEEE Trans. 2018, 44, 79-83.

17. Xiong, Y.F.; Chen, L.J.; Zheng, T.W. Optimal configuration of hydrogen energy storage in comprehensive energy system of low-carbon industrial park considering the coupling characteristics of electricity and heat. Electr. Power Autom. Equip. 2021, 41, 31-38.

18. Chen, J.P.; Hu, Z.J.; Chen, Y.G. Thermoelectric optimization of integrated energy system considering stepped carbon trading mechanism and electric hydrogen production. Electr. Power Autom. Equip. 2021, 41, 48-55.

19. Jiao, S.M.; Qiao, X.B.; Li, Y. Combined optimization of power-to-gas equipment and photovoltaic, taking into account the life-cycle carbon emissions and carbon trading of the integrated energy system. Electr. Power Autom. Equip. 2021, 41, $156-163$.

20. Haider, Z.M.; Mehmood, K.K.; Khan, S.U.; Khan, M.O.; Wadood, A.; Rhee, S.-B. Optimal Management of a Distribution Feeder during Contingency and Overload Conditions by Harnessing the Flexibility of Smart Loads. IEEE Access 2021, 9, 40124-40139. [CrossRef] 